\title{
MINIMASI BIAYA TRANSPORTASI BERAS MISKIN (RASKIN) DENGAN MENGGUNAKAN METODE PEUGASAN PADA PERUM BULOG KILANG JAMPALAN
}

\author{
Yulia Purnama Sari Hutagaol \\ Mahasiswa Program Studi Sistem Informasi, STMIK Royal Kisaran \\ email : yuliapurnama@gmail.com
}

\begin{abstract}
There are also assignment issues discussing the place of the starting point of the process of running a source to a number of objectives, which aims to increase production or profit. In the assignment problem there are important things that must be considered in doing a job in the field of company. So that later the company can condition assignments so that production costs and excess production time can be minimized. Therefore to minimize production costs can be done by solving assignment problems. Because the assignment problem requires that every job only do one job and only focus on tasks that have been given so the task can be done with maximum results.
\end{abstract}

Keywords: Assignment Method

\begin{abstract}
Abstrak : Ada pun permasalahan penugasan membahas tentang tempat titik awal proses berjalannya sebuah sumber ke sejumlah tujuan, yang mana bertujuan untuk meningkatkan hasil produksi atau keuntungan. Dalam masalah penugasan ada terdapat hal yang penting yang harus bisa dipertimbangkan dalam melakukan sebuah pekerjaan dalam bidang perusahaan. Agar nantinya perusahaan dapat mengkondisikan penugasan agar biaya produksi dan kelebihan waktu produksi dapat diminimumkan. Oleh karena itu untuk meminimumkan biaya produksi dapat dilakukan dengan penyelesaian permasalahan penugasan. Karena masalah penugasan mengharuskan pada setiap suatu pekerjaan hanya melakukan satu pekerjaan dan hanya fokus pada tugas yang teah diberikan dengan begitu tugas tersebut dapat dilakukan dengan hasil yang maksimal.
\end{abstract}

Kata Kunci : Metode Penugasan

\section{PENDAHULUAN}

Minimasi Biaya Transportasi Beras Miskin (Raskin) pada kasus kali ini memiliki 4 Truk yang mana nantinya harus menyalurkan Beras Raskin pada 3 kota, yaitu Kota Asahan, Kota Labura, dan Kota Tanjung Balai. Disetiap kota tersebut akan menentukan berapa banyak mereka membutuhkan Beras Raskin dengan mengetahui berapa banyak dikota tersebut masyarakatnya yang tidak mampu atau yang berkecukupan sangat rendah. Prusahaan akan meminta data yang real pada utusan setiap kota, maka dari itu disetiap kota tersebut akan diminta data yang real agar perusahaan dapat mengetahui berapa banyak Beras Raskin yang akan dibutuhkan pada setiap kota tersebut.

Ninda Uswatun K (2012) dalam penelitiannya membahas tentang penugasan tidak seimbang 
DOI : https://doi.org/10.33330/jurteksi.v5i1.311

Available online at http://jurnal.stmikroyal.ac.id/index.php/jurteksi

menggunakan metode Pinalti. Penelitian Ninda menghasilkan baha metode penugasan pinalti lebih efektif dibandingkan dengan metode Hungarian dan metode simpeks. Ha tersebut terlihat dari cara perhitungan dan iterasi yang lebih sedikit dibandingkan metode Hungarain dan Metode simpleks.

\section{METODE}

Model penugasan (Assigment) pada awalnya dikenal sebagai Hungarain Method. Istiah ini diberikan untuk mengabdikan D. Koning, ahi matematika asal Hungaria yang pertama kai mengembangkan model ini (Siswanto, 2007). Thomas J. Kakiay (2008) menyatakan bahwa masalah penugasan adalah alokasi dari banyak pekerjaan atau individu pekerja yang dinyatakan dengan $M$ untuk mengerjakan pekerjaan atau esin dengan unit atau biaya yang sudah ditentukan.

Metode penugasan akan digunakan untuk mamaksimalkan keuntungan dalam suatu perusahaan. Ada beberapa hal yang harus perusahaan ketahui dalam menyelesaikan masalah dalam penugasan yaitu: Jumlah Truk, Jumlah Pekerja, Pekerjaan yang akan diselesaikan, Penugasan Pekerja pada suatu pekerjaan, Parameter tempat penugasan.

\section{Masalah Minimisasi}

Adapun masalah pada penugasan minimisasi, Dan beberapa hal yang harus diketahui yaitu;

1. Menyusun pada tabel biaya
2. Lakukan pengurangan pada baris, dengan cara:

a) Pilih nilai yang terendah pada disetiap baris

b) Lakukan pengurangan pada setiap nilai dengan nilai terendah yang sudah dipilih pada setiap barisnya.

c) Lakukan pengurangan pada setiap kolom dengan nilai terendah yang sudah dipilih pada setiap kolomnya.

3. Selanjutnya, Tarik sejumlah garis horizontal atau vertikal seminimum mungkin pada kolom untuk mencoret semua nilai yang memiliki angka nol pada tabel biaya.

4. Lakukan pengecekkan pada tabel :

a) Jika jumlah pada garis yang diproleh tidak sama dengan jumlah baris/kolom maka tambahi satu baris/kolom pada tabel agar seimbang.

b) Jika jumlah pada garis yang diproleh sama dengan jumlah baris/kolom maka penugasan sudah optimal.

c) Jika jumlah pada garis yang diproleh tidak sama dengan jumlah baris/kolom maka hal yang harus dilakukan yaitu pilih nilai yang terendah dari semua nilai yang tidak dilewati garis dengan mengurangkan semua nilai tersebut dengan nilai terendah yang terpilih.

d) Tambahkan nilai yang berada pada perpotongan garis dengan nilai terendah yang terpilih tadi. 
e) Nilai yang dilewati garis tetapi tidak berada pada perpotongan maka nilai tersebut tidak berubah.

f) Lakukan pengecekkan pada tabel kembali, Jika belum optimal maka lakukan perulangan langkah-langkah tersebut sampai mendapatkan niai yang optimal.

Pada kasus persoalan ini dimana jumlah baris tidak sama dengan kolom maka, harus menyeimbangkan jumlah baris dan kolomnya dengan menambah variabel dummy bernilai nol pada baris atau kolom. Dengan ketentuan:

1. Jika jumlah baris lebih sedikit dari pada jumlah kolom maka, variabel dummy ditambahkan pada baris.

2. Jika jumlah kolom lebih sedikit dari pada jumlah baris maka, variabel dummy ditambahkan pada kolom.

3. Setelah jumlah baris sama dengan jumlah kolom maka, yang akan dilakukan yaitu melanjutkan langkah-langkah seperti peyelesaian sebelumnya tetapi, untuk variabel dummy tidak perlu dikurangkan dengan nilai terendah.

\section{Masalah Maksimisasi}

Pada masalah pada penugasan maksimisasi, Ada beberapa hal yang harus diketahui yaitu :

1. Melakukan penyederhanaan pada masalah maksimisasi dalam bentuk metode penugasan.

2. Menentukan nilai tertinggi dari setiap baris, lalu lakukan pengurangan nilai dengan setiap nilai yang pada baris yang sama.

3. Periksa kembali apakah setiap kolom telah mempunyai nilai 0 , Jika sudah lanjutkan ke langkah 4, jika belum kurangkan setiap kolom yang belum memiliki nilai nol dengan nilai terkecil.

4. Berikan tanda pada garis atau kolom yang mempunyai nilai nol dengan cara memilih baris atau kolom yang memiliki nol terbanyak terlebih dahulu untuk mendapatkan garis seminimal mungkin. Jika jumlah garis sudah sama dengan jumlah baris atau kolom maka tabel telah optimal.

5. Baris/kolom yang hanya memiliki 1 nilai nol merupakan penugasan terbaik, kemudian diikuti dengan memilihi salah satu dari nilai yang memilki lebih dari 1 nolnya untuk dijadikan penugasan.

\section{PEMBAHASAN}

Pada kasus kali ini perusahaan Kilang Beras Raskin memiiki 4 truk yang mana truk tersebut harus menyalurkan Beras Raskin ke 3 kota yaitu Kota Asahan, Kota Labura, dan Kota Tanjung Balai.

Kemudian perusahaan tersebut akan memproleh data dari ke 3 truk yang mana truk-truk tersebut nantinya akan mengirim atau menyalurkan Beras Raskin ke 3 kota tersebut :

\section{Solusi :}

Dari permasalahan penugasan 
DOI : https://doi.org/10.33330/jurteksi.v5i1.311

Available online at http://jurnal.stmikroyal.ac.id/index.php/jurteksi

di atas, kita lihat bahwa kota tersebut menentukan penilaian yang tidak maksimal untuk menentukan biaya transportasi truk maka jenis masalahnya berupa maksimisasi. Diketahui pula bahwa Ttuk sebagai sumber yang akan ditugaskan dan ada 4 truk yang akan ditugaskan dalam masalah ini dan akan ditempatkan pada ke 3 Kota. Hal ini menunjukan baris $\neq$ kolom sehingga baris dan kolomnya perlu diseimbangkan terlebih dahulu dengan menambahkan Dummy pada kolom baris, sebagai berikut:

\begin{tabular}{c|c|c|c}
\hline \multirow{2}{*}{ Truk } & \multicolumn{3}{|c}{ Kota } \\
\cline { 2 - 4 } & Asahan & Labura & Tanjung Balai \\
\hline 1 & 8 & 9 & 4 \\
\hline 2 & 5 & 8 & 4 \\
\hline 3 & 4 & 9 & 3 \\
\hline 4 & 4 & 3 & 8 \\
\hline
\end{tabular}

\begin{tabular}{c|c|c|c|c}
\hline \multirow{2}{*}{ Truk } & \multicolumn{4}{|c}{ Kota } \\
\cline { 2 - 5 } & Asahan & Labura & Tanjung Balai & Dummy \\
\hline 1 & 8 & 9 & 4 & 0 \\
\hline 2 & 5 & 8 & 4 & 0 \\
\hline 3 & 4 & 9 & 3 & 0 \\
\hline 4 & 4 & 3 & 8 & 0 \\
\hline
\end{tabular}

solusi telah diperoleh hasilnya.

\begin{tabular}{c|c|c|c|c}
\hline \multirow{2}{*}{ Truk } & \multicolumn{4}{|c}{ Kota } \\
\cline { 2 - 5 } & Asahan & Labura & Tanjung Balai & Dummy \\
\hline 1 & 0 & 1 & 4 & 0 \\
\hline 2 & 2 & 0 & 3 & 0 \\
\hline 3 & 4 & 0 & 5 & 0 \\
\hline 4 & 4 & 6 & 0 & 1 \\
\hline
\end{tabular}

a. Penugasan pada setiap truk yang harus diambil perusahaan untuk memproleh biaya transportasi.

Truk 1 akan ditepatkan pada Kota Asahan

Truk 2 akan ditepatkan pada Kota Labura
Truk 3 akan ditepatkan pada Dummy

Truk 4 akan ditepatkan pada Kota Tanjung Balai

Dengan penilaian :

\begin{tabular}{|c|c|c|}
\hline Truk & Kota & Nilai \\
\hline 1 & Asahan & 8 \\
\hline 2 & Labura & 8 \\
\hline 3 & Dummy & 0 \\
\hline 4 & Tanjung Balai & 8 \\
\hline \multicolumn{2}{|c|}{ Jumlah } & 24 \\
\hline
\end{tabular}


DOI : https://doi.org/10.33330/jurteksi.v5i1.311

Available online at http://jurnal.stmikroyal.ac.id/index.php/jurteksi

\section{\begin{tabular}{|cc|}
\hline Rata-rata Maksimal & 6 \\
IMPLEMENTASI & Gambar 3. Form Distribusi
\end{tabular}}

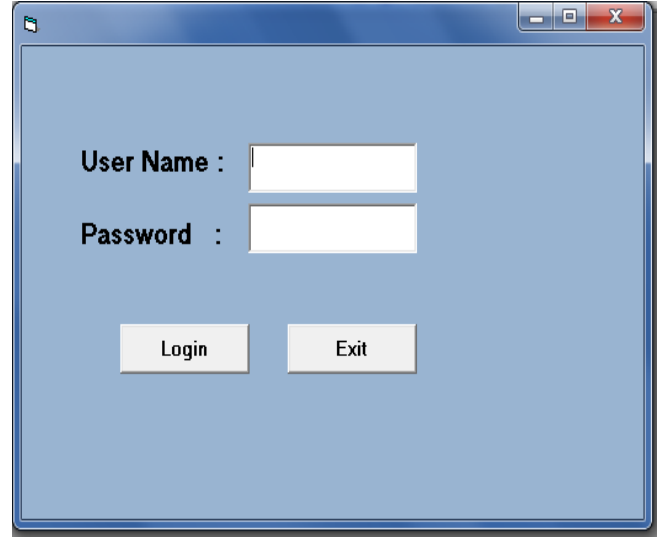

Gambar 1. Form Login

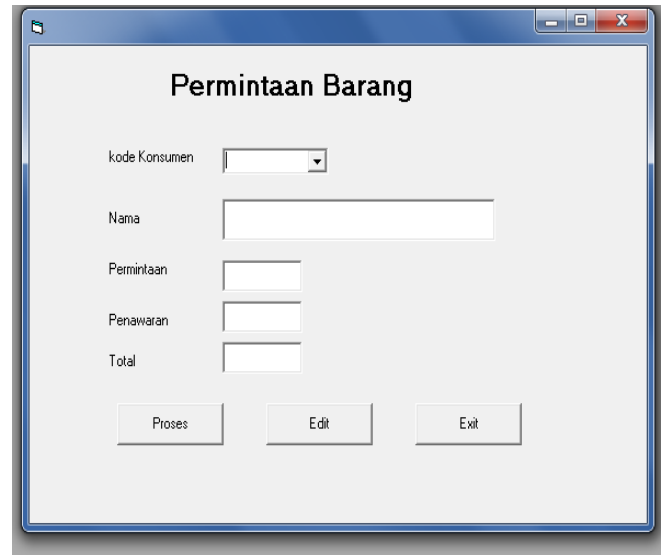

Gambar 2. Permintaan Barang

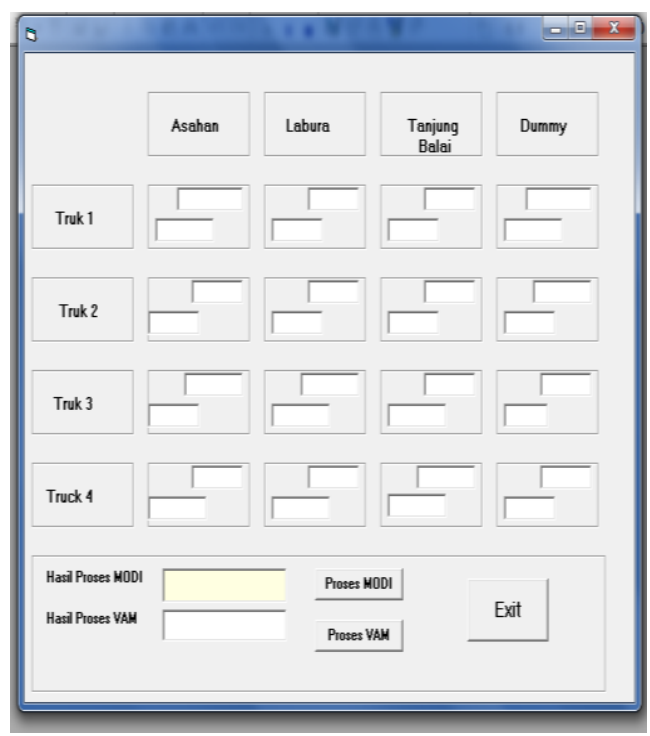

\section{KESIMPULAN}

Berdasarkan pembahasan, Masalah penugasan adalah salah satu kasus khusus dari masalah transportasi. Pada kasus kali ini untuk menyelesaikan masalahnya menggunakan metode penugasan. Dengan kondisi apabila jumlah baris tidak sama dengan jumlah kolom maka kita perlu menyeimbangkannya dengan menambahkan variabel Dummy. Masalah penugasan dapat berupa masalah minimisasi atau maksimisasi.

Dari permasalahan penugasan ini, penempatan pada truk masalahnya berupa maksimisasi dimana truk akan menyalurkan Beras Raskin pada ke 3 kota. Truk ingin menentukan penilaian yang maksimal untuk dapat mengetahui berapa banyak Beras Raskin yang akan disalurkan pada setiap kota. Dengan begitu maka hal yang harus dilakukan ialah mengunakan variabel dummy yang semua nilainya adalah nol. Setelah melalui langkah-langkah penyelesaian yang ada bahwa Truk 1 akan ditempatkan di kota Asahan, Truk 2 ditempatkan pada kota Labura, Truk 3 ditempatkan pada kota Dummy dan Truk 4 akan ditempatkan pada Kota Tanjung Balai. Dengan rata-rata penilaian maksimal yang dihasilkan adalah 6 .

\section{DAFTAR PUSTAKA}

1. Basriati, Sri, Lestari, Ayu. 2019. Penyelesaian 
DOI : https://doi.org/10.33330/jurteksi.v5i1.311

Available online at http://jurnal.stmikroyal.ac.id/index.php/jurteksi

penugasan menggunakan metode Hungarian dan Pinalti. Kisaran https://caridokumen.com

2. Iriani Kehi, Magdalena. 2016. Penerapan Metode Penugasan
Terhadap Penempatan Dosen Pengampuh Di Universitas Prima. Surabaya. https://caridokumen.com 